\title{
High-Efficiency Noble Gas Electron Impact Ion Source for Isotope Separation
}

\author{
A. D. Appelhans \\ J. E. Olson \\ D. A. Dahl \\ M. B. Ward \\ July 2016
}

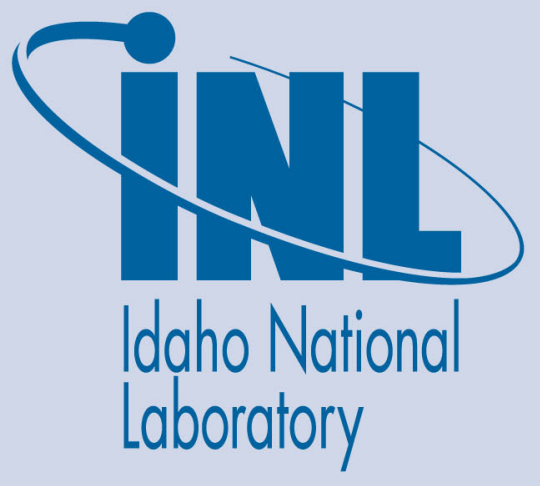

The INL is a U.S. Department of Energy National Laboratory operated by Battelle Energy Alliance 


\section{DISCLAIMER}

This information was prepared as an account of work sponsored by an agency of the U.S. Government. Neither the U.S. Government nor any agency thereof, nor any of their employees, makes any warranty, expressed or implied, or assumes any legal liability or responsibility for the accuracy, completeness, or usefulness, of any information, apparatus, product, or process disclosed, or represents that its use would not infringe privately owned rights. References herein to any specific commercial product, process, or service by trade name, trade mark, manufacturer, or otherwise, does not necessarily constitute or imply its endorsement, recommendation, or favoring by the U.S. Government or any agency thereof. The views and opinions of authors expressed herein do not necessarily state or reflect those of the U.S. Government or any agency thereof. 
INL/EXT-16-39503

Revision 0

\title{
High-Efficiency Noble Gas Electron Impact lon Source for Isotope Separation
}

\author{
A. D. Appelhans, J. E. Olson, D. A. Dahl, and M. B. Ward
}

July 2016

Idaho National Laboratory

Energy and Environment Science and Technology Idaho Falls, Idaho 83415

http://www.inl.gov

Prepared for the

U.S. Department of Energy

Under DOE Idaho Operations Office

Contract DE-AC07-05ID14517 

Energy and Environment Science and Technology

\section{High-Efficiency Noble Gas Electron Impact Ion Source for Isotope Separation}

INL/EXT-16-39503

Revision 0

July 2016

Approved by:
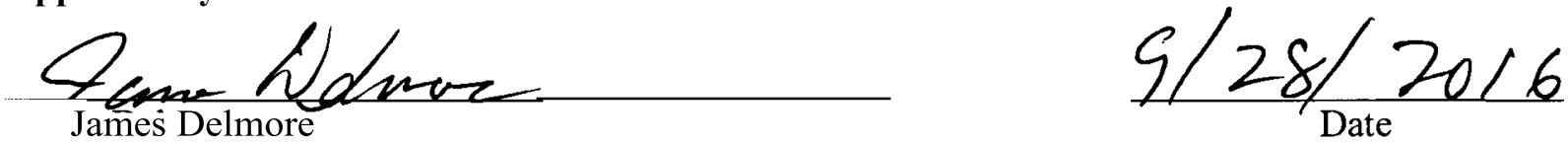


\begin{abstract}
An electron impact ion source has been designed for generation of noble gas ions in a compact isotope separator. The source utilizes a circular filament that surrounds an ionization chamber, enabling multiple passes of electrons through the ionization chamber. This report presents ion optical design and the results of efficiency and sensitivity measurements performed in an ion source test chamber and in the compact isotope separator. The cylindrical design produced xenon ions at an efficiency of $0.37 \%$ with a sensitivity of $\sim 24 \mu \mathrm{A} / \mathrm{Pa}$ at $300 \mu \mathrm{A}$ of electron current.
\end{abstract}

Key words: electron impact ion source, noble gas ion source, xenon, SIMION 


\section{ACKNOWLEDGEMENTS}

The authors thank D. Jenson and M. Watrous for preparation of the stable xenon mixtures and assistance with the radioactive xenon samples. 


\section{CONTENTS}

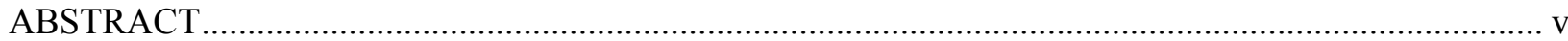

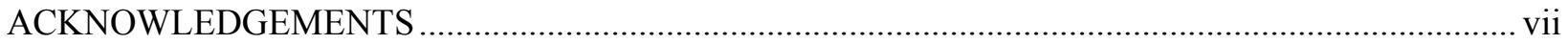

ACRONYMS

Error! Bookmark not defined.

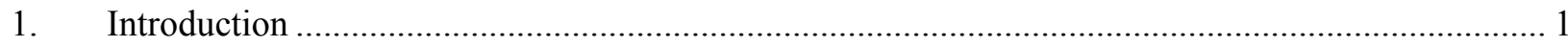

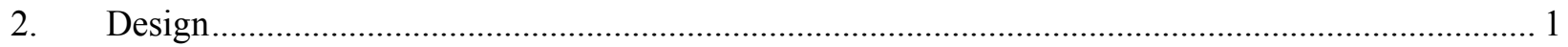

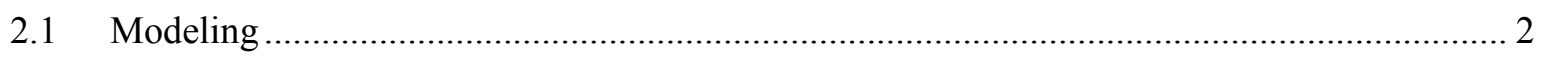

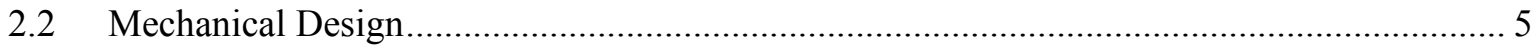

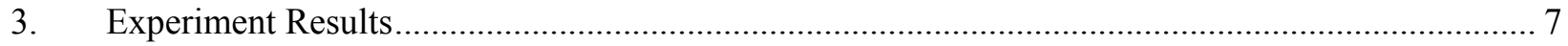

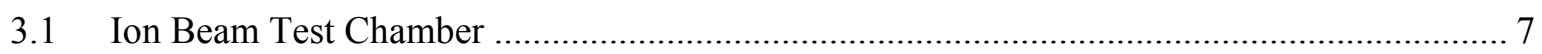

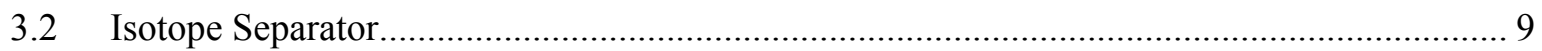

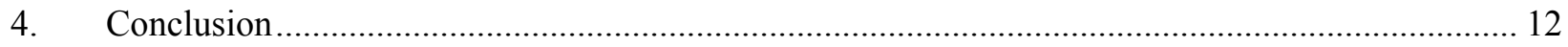

\section{FIGURES}

Figure 1. SIMION model of the ion source showing the major components; scale is 0.127 millimeters per grid unit.

Figure 2. Potential energy surface view for (top) an electron and (bottom) an ion. Lower frame also shows a set of contour lines within the ionization cage. 4

Figure 3. A set of positive ion trajectories for ions generated randomly within the ionization cage (left) and a trajectory for an electron emitted from the filament (right).

Figure 4. SIMION model of the ion source mounted on the univoltage ion gun and a set of ion trajectories.

Figure 5. Mechanical drawing of the ion source; shaded areas are insulating sleeves.

Figure 6. Photographs of (clockwise from upper left) the ionization cage, filament mount, filament flange assembly, assembled ion source with gas introduction line and ion source mounted on the ion gun.

Figure 7. SIMION model of the separation of the ion beams using the ion source test chamber. Note that the individual isotopes are not separated, thus the Xe beam contains all of the xenon isotopes.

Figure 8. Measured mass spectrum (top) in the ion source test chamber and the SIMION-

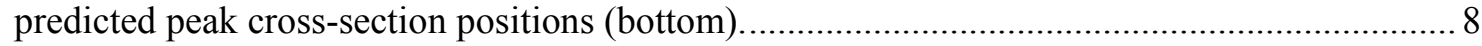

Figure 9. Mass spectrum of the source chamber taken with a residual gas analyzer................................. 8

Figure 10. Measured fluence of xenon ions as a function of time. ...................................................... 9

Figure 11. Measured total xenon ion current as a function of the xenon pressure in the ion source housing; the equation is for the best linear fit to the data. 
Figure 12. SIMION-predicted kinetic energy distribution for xenon ions generated with the ionization cage at 30 volts above the exit aperture. The plot displays the percent of ions as a function of the kinetic energy difference from the mean.

Figure 13. Mass spectrum of $\sim 2$ ppm natural xenon in air taken in the isotope separator........................ 11 


\section{High-efficiency Noble Gas Electron Impact lon Source for Isotope Separation}

\section{Introduction}

Electron impact ion sources have been used for many years in mass spectrometry. Nier published a design in $1940^{1}$ that has been the cornerstone of many subsequent designs, now commonly referred to as Nier-type ion sources. These and their variants have remained the standard for commercial noble gas mass spectrometers. The efficiency (ions produced per neutral atom introduced into the source) of these ion sources typically ranges from $1 \times 10^{-3}\left(\mathrm{CO}_{2}\right)^{2}$ to $1 \times 10^{-5}\left({ }^{132} \mathrm{Xe}\right)^{3}$. Utilizing a thin beam of electrons constrained with a small magnetic field, these ion sources are able to produce ion beams with a relatively low energy spread, which is important for high resolution mass spectrometry. Other designs have been proposed - among them the Baur source ${ }^{4}$, which utilizes a rotationally symmetric electron filament and a charcoal electron sink. This source has a reported sensitivity of $\sim 9 \mu \mathrm{A} / \mathrm{Pa}$ for argon. A modified version of the Baur source has been reported to have a sensitivity of $52 \mu \mathrm{A} / \mathrm{Pa}$ at $250 \mu \mathrm{A}$ of electron current ${ }^{5}$.

An ion source was required for use in separating xenon fission gas isotopes using a low-energy, compact isotope separator. The two primary objectives in the ion source design were high efficiency (to reduce the amount of radioactive gas handled) and simplicity of design and operation. Since the primary radioisotope of interest was ${ }^{133} \mathrm{Xe}$, and the ${ }^{132} \mathrm{Xe}$ and ${ }^{134} \mathrm{Xe}$ isotopes are stable, only a very modest mass resolution was required of the mass separator. One implication of this was that the requisite energy spread of the ion source could be relaxed, offering an opportunity for increasing the source efficiency. The second objective, simplicity of design and operation, mitigated potential issues for an electron impact ionization source. There are other source designs (microwave plasma ${ }^{6}$, electron capture resonance ${ }^{7}$ ) with high efficiency, but these were deemed more complex both in design and operation than required. Accordingly, a cylindrical cage electron impact ion source was designed and tested; the ion source is now used on the xenon mass separator. This paper describes the design of the ion source, illustrates the ion optical performance, and presents the results of efficiency tests conducted in an ion gun test chamber and on the mass separator.

\section{Design}

In an electron impact ion source, the electrons must be accelerated to an energy adequate to ionize the gas of interest; this is typically between 50 and $100 \mathrm{eV}$. The ionization efficiency will be determined by the cross-section for an interaction and the length of the path over which the interaction can occur. Thus,

1 A. O. Nier, “A Mass Spectrometer for Routine Isotope Abundance Measurements,” Rev. Sci. Instrum., Vol. 11, 1940, pp. 212-16.

$2 \mathrm{CO}_{2}$ specification for the Finnigan MAT 253.

3 A. O. Nier and D. J. Schlutter, "High-Performance Double-Focusing Mass-Spectrometer," Rev. Scientific Instr., Vol. 56, No. 2, 1985, pp. 214-219.

4 H. Baur, Doctoral Dissertation, 1980, Technischen Hochschule, Zurich; translation, LA-TR-83-25.

5 C. M. Hohenberg, "High Sensitivity Pulse-Counting Mass-Spectrometer System for Noble Gas Analysis," Rev. Sci. Instrum., Vol. 51, 1980, pp. 1075-1082.

6 J. Poths and E. P. Chamberlin, "A High-Efficiency Ion Source for Kr and Xe Isotopic Measurements," Int. J. Mass Spectrom., Vol. 146/147, 1995, pp. 47-54

7 G. Gaubert, C. Baru, C. Canet, J. Cornell, M. Dupuis, W. Farabolini, J. L. Flambard, P. Gorel, P. Jardin, N. Lecesne, P. Leherissier, F. Lemagnen, R. Leroy, J. Y. Pacquet, M. G. Saint-Laurent, and A. C. C. Villari, "Minimono: An Ultracompact Permanent Magnet Ion Source for Singly Charged Ions," Rev. Sci. Instr., Vol 74, No. 2, 2003, pp. 956-960. 
in conventional designs, a transverse magnetic field is applied that both constrains the electron path across the ionization chamber (keeping the resultant ion energy distribution tight) and causes the electrons to take a spiraling trajectory (effectively increasing the path length). However, in these designs the electrons make only a single pass across the ionization chamber and are then captured in an electron trap. By controlling the electron filament current, based on the trapped electron current, a stable output can be maintained.

Since the mass resolution requirement of the isotope separator did not necessitate a tight electron energy distribution, the stringent geometry constraints could be relaxed. In an attempt to enable multiple passes of an electron through the ionization region, a cylindrical approach was explored.

\subsection{Modeling}

The SIMION ${ }^{8}$ ion optical modeling program was used to investigate the design concept and develop a final design for testing. Figure 1 illustrates the basic design of the ion source. There is a central cage, the ionization chamber, into which the neutral gas is directed. The cage is held at a potential (typically $30 \mathrm{~V}$ ) above an isolated end cap with a central aperture held at high voltage $(5 \mathrm{kV})$. This geometry forms a potential gradient inside the cage toward the aperture through which the ions formed in the cage are accelerated into the ion gun. The electrons are generated from a filament that surrounds the cage and is at a potential lower than the cage (by typically $100 \mathrm{~V}$ ); thus, the electrons are accelerated into the cage. The potential difference between the filament and the cage defines the kinetic energy of the electrons inside the cage. Surrounding the cage-filament assembly is another cylinder, called the repeller, which is held at a potential $(10 \mathrm{~V})$ below the filament. This repels electrons emitted from the filament toward the cage. Electrons that are accelerated into the ionization cage and pass through it are repelled by the repeller electrode back into the cage, and consequently have the opportunity to make many passes. An electron will eventually interact with an ion and lose energy, or strike a cage wire or the filament and be lost. A statistical analysis shows that, for an open grid area of $95 \%$, an electron makes an average of 10 passes through before a collision with a grid wire occurs. A benefit of a larger ionization area, as offered by the cylindrical cage (compared to the electron sheath of the Nier-type source), is that the total number of electrons within the area can be greater without space charge becoming a problem. Because the field gradient in the ionization cage is low, the ions that hit the exit aperture plate have not attained sufficient energy to be implanted and are expected to neutralize and be available for ionization once again; this is another efficiency-enhancing measure.

8 D. A. Dahl, “SIMION for the Personal Computer in Reflection,” Int. J. Mass Spectrom., Vol. 200, 2000, pp. 3-25. 


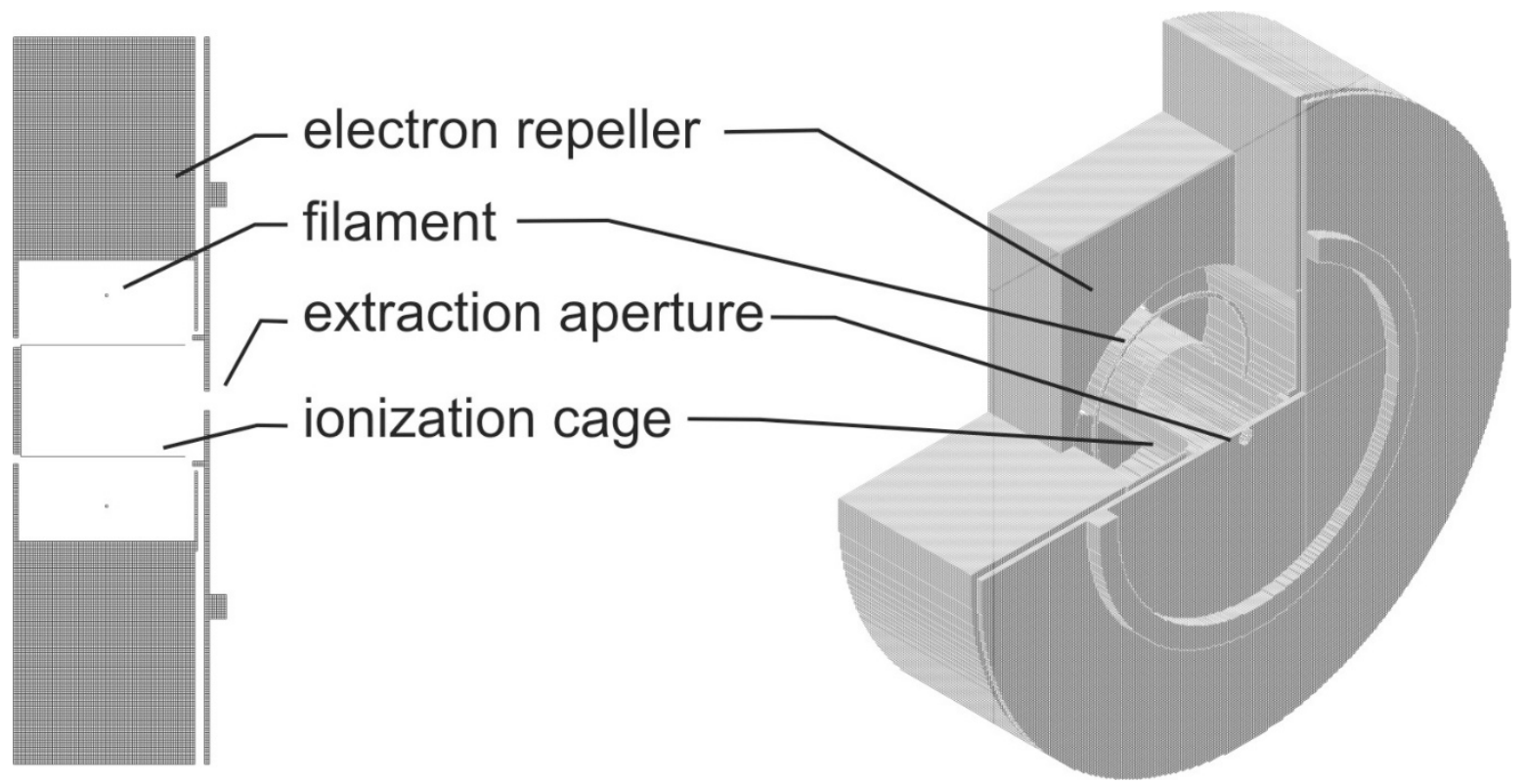

Figure 1. SIMION model of the ion source showing the major components; scale is 0.127 millimeters per grid unit.

Figure 2 shows several potential energy surface views of the SIMION model of the ion source; the top frame shows the potential energy surface for an electron; the bottom frame shows the surface for a positive ion inside the cage. Figure 3 shows a set of ion trajectories as they are extracted from the cage through the aperture and an electron trajectory (only one is shown for clarity) for an electron emitted from the filament. The ion source is designed to be installed on an ion gun developed previously in our group - the univoltage ion gun ${ }^{9}$. Figure 4 shows a cross-section of the model of the ion source mounted on the univoltage ion gun and a set of ion trajectories. The ion gun typically has a transmission efficiency of $100 \%$, and includes an Einzel lens on the exit for beam shaping.

9 D. A. Dahl, A. D. Appelhans, M. B. Ward, “A Modular Ion Beam Deflector,” Int. J. Mass Spectrom. Ion Process., Vol. 189, No. 1, 1999, pp. 47-51. 

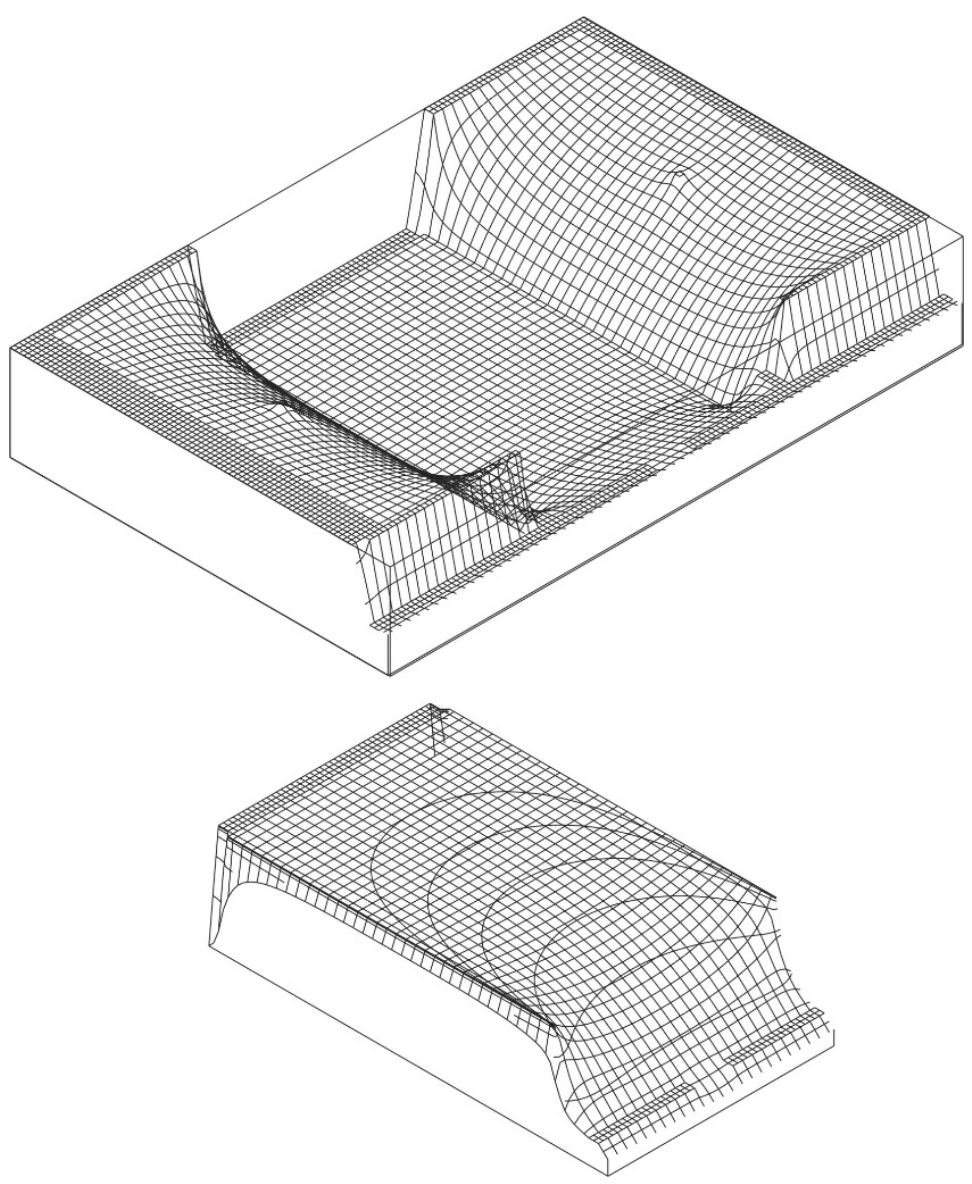

Figure 2. Potential energy surface view for (top) an electron and (bottom) an ion. Lower frame also shows a set of contour lines within the ionization cage. 

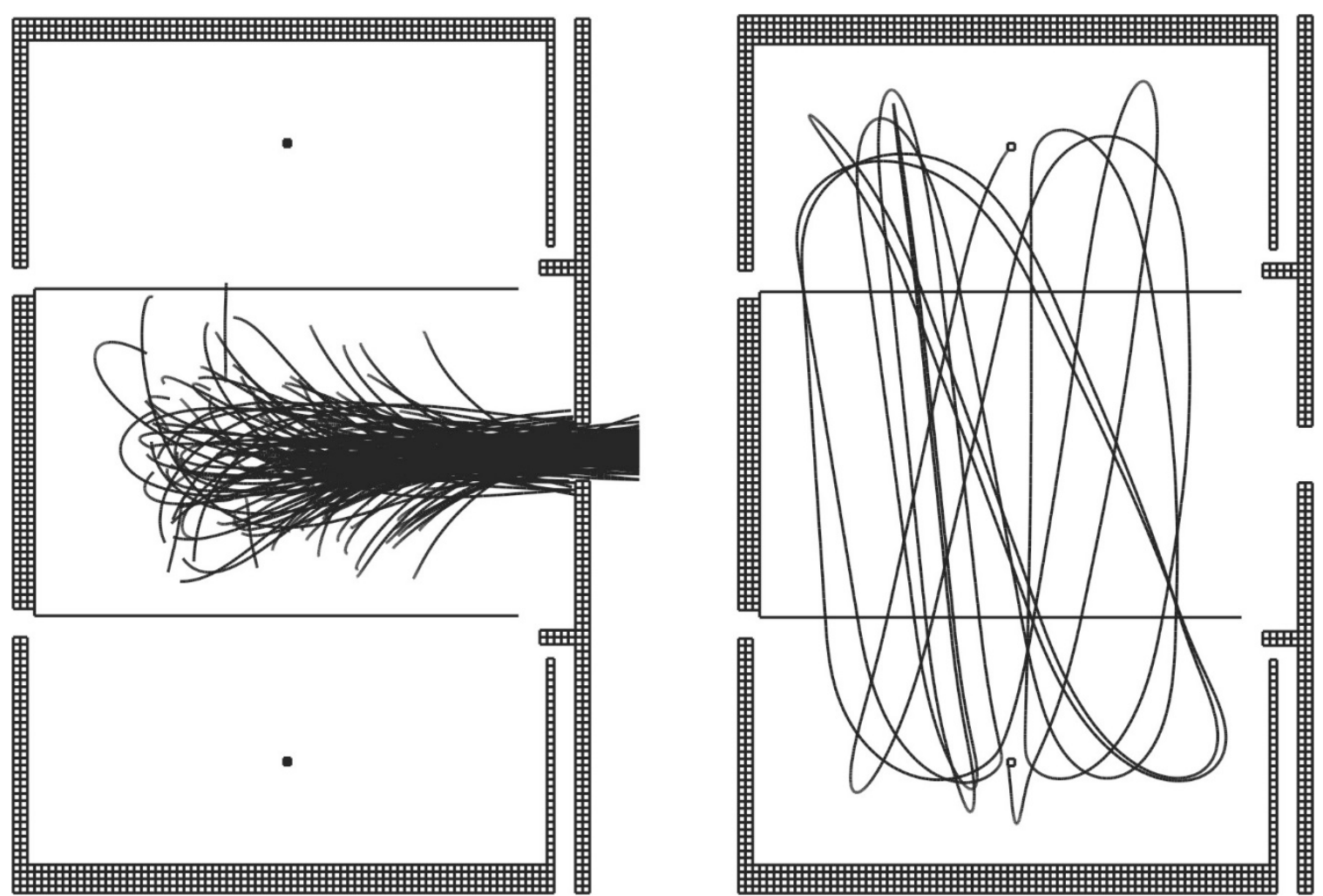

Figure 3. A set of positive ion trajectories for ions generated randomly within the ionization cage (left) and a trajectory for an electron emitted from the filament (right).

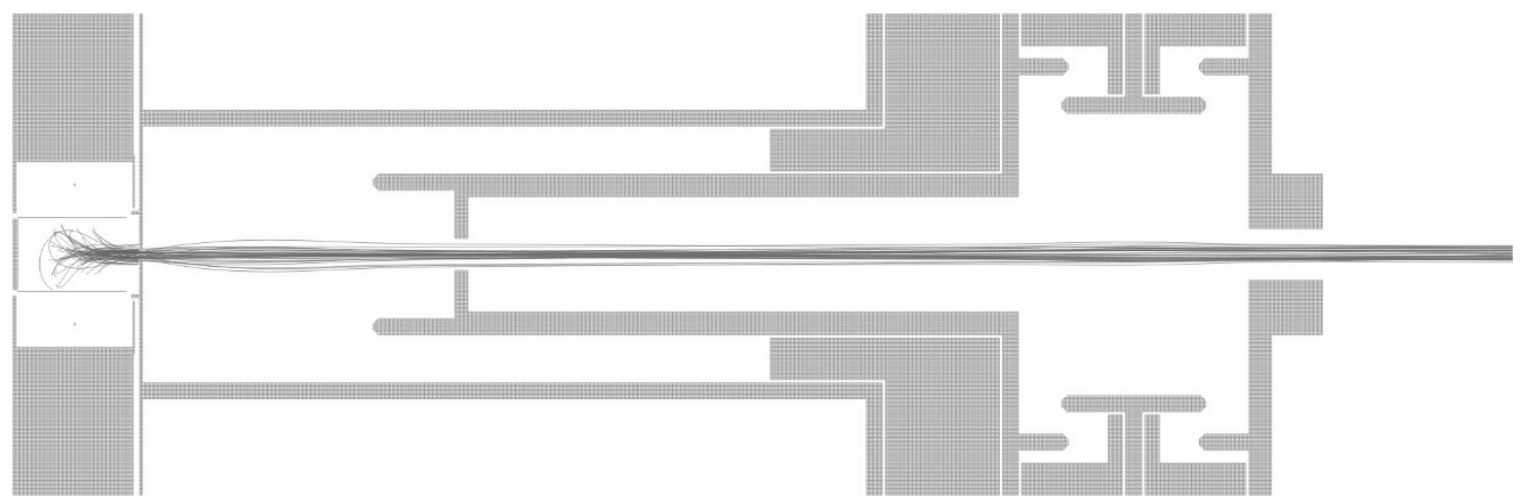

Figure 4. SIMION model of the ion source mounted on the univoltage ion gun and a set of ion trajectories.

\subsection{Mechanical Design}

Figure 5 shows a line drawing cross-section of the ion source, and Figure 6 shows a series of photographs of the ion source components and the assembled source mounted on the ion gun. The ionization cage was made using a stainless steel framework onto which a high pass grid of Ni wire was spot welded ${ }^{10}$. The gridded cage was spot welded onto a base flange that contained the gas inlet. The filament was made from Re wire shaped into a loop and held in place with insulating ceramic tubes

\footnotetext{
${ }^{10}$ Fabricated by Fleeners Tool and Engineering, 5537 Earl Young Rd., Bloomington, IN 47408.
} 
captured between the two halves of the electron repeller shell. In assembly, the filament is captured in the repeller shell, with its two halves being held together with small screws. The exit flange contains the ion extraction aperture and a set of ceramic tube insulators that isolate it from the filament and repeller assembly. Another set of insulators isolate the cage flange from the filament repeller assembly, and three screws, isolated with ceramic washers, pass through the entire assembly and connect it to the ion gun. A small-diameter stainless steel tube connects the ion source to the gas inlet valve high-voltage break. The electronics for the source are straightforward; a single, high-voltage power supply driving a voltage divider is used with a floating filament supply and one $9 \mathrm{v}$ battery to operate the ion source and ion gun.

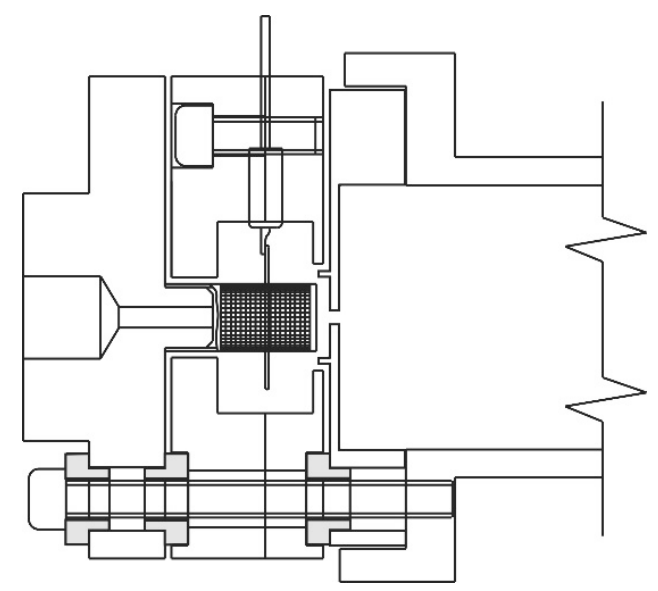

Figure 5. Mechanical drawing of the ion source; shaded areas are insulating sleeves.
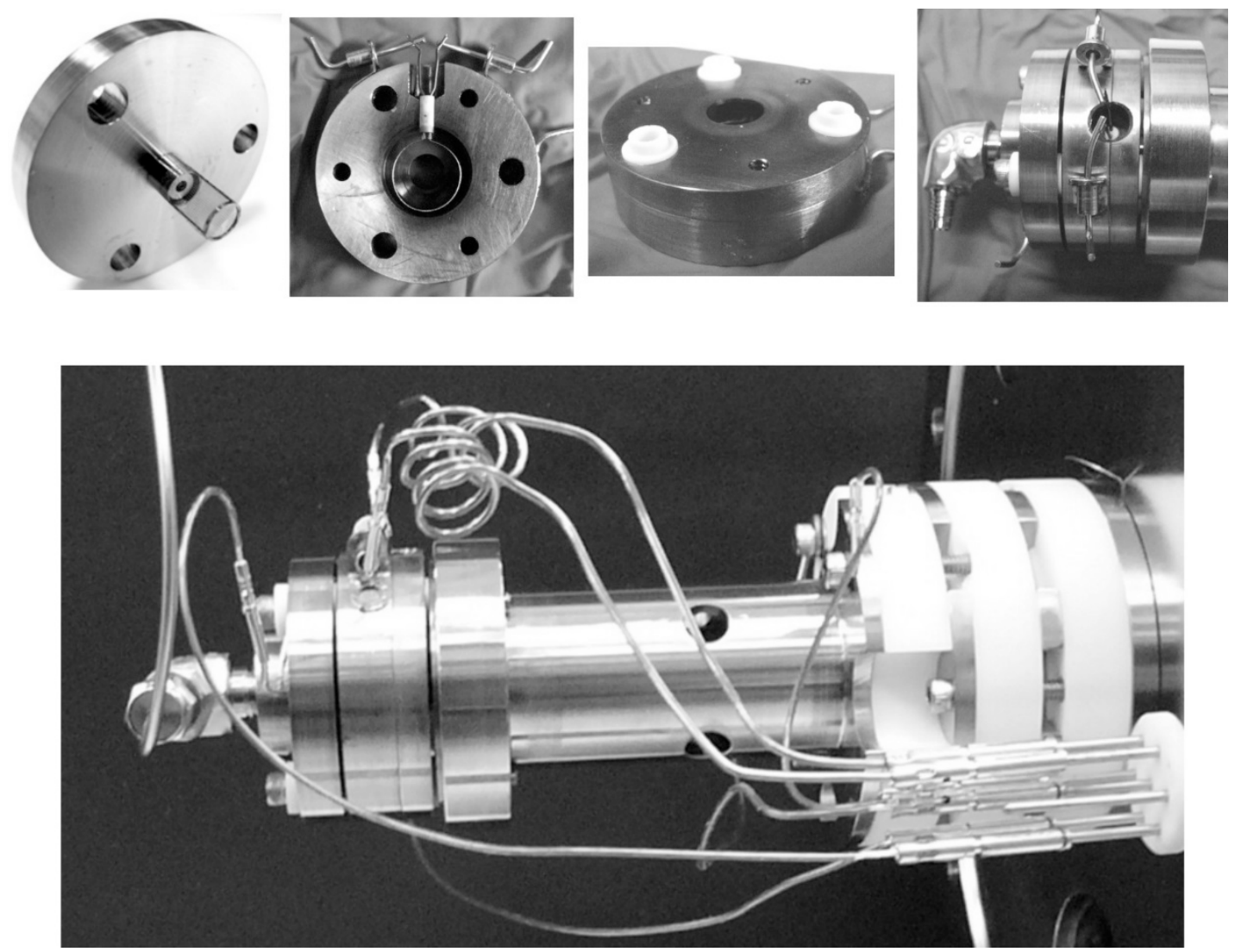

Figure 6. Photographs of (clockwise from upper left) the ionization cage, filament mount, filament flange assembly, assembled ion source with gas introduction line and ion source mounted on the ion gun. 


\section{Experiment Results \\ 3.1 Ion Beam Test Chamber}

Initial measurements of the ion source performance were conducted in an ion beam test chamber. The ion source and accelerating lens were mounted on a platform that included a small magnet adequate to separate the xenon isotopes from the other ions produced in the source. The resolution was not sufficient to separate the individual xenon isotopes. Figure 7 shows the SIMION-predicted ion trajectories of the mass separated beams for ions of (bottom to top) water, nitrogen, $\mathrm{CO}_{2}$, doubly charged xenon, and singly charged xenon. The acceleration voltage was $3 \mathrm{kV}$. The separation between the beams allowed the total xenon ion signal to be measured without interference from the background species.

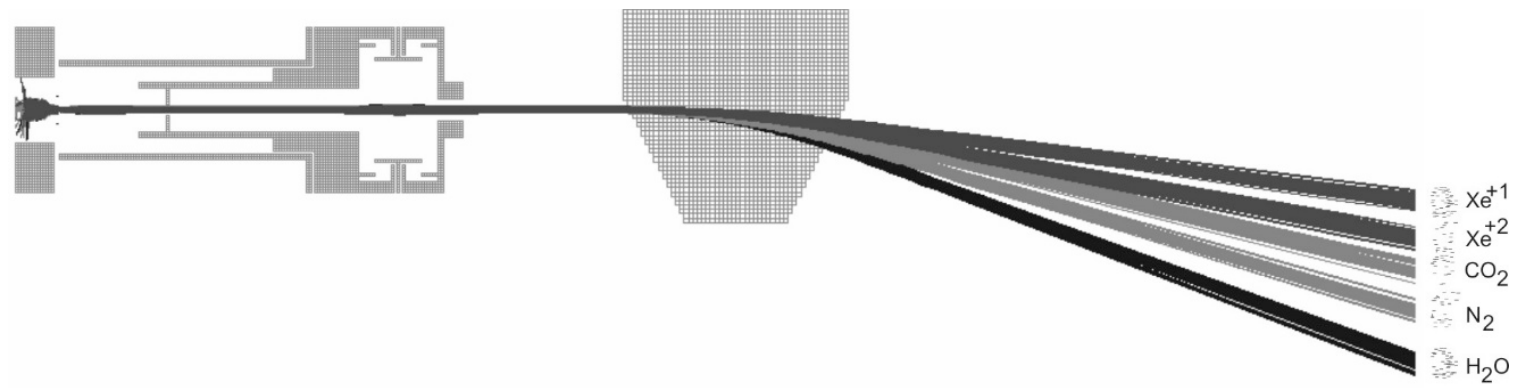

Figure 7. SIMION model of the separation of the ion beams using the ion source test chamber. Note that the individual isotopes are not separated, thus the Xe beam contains all of the xenon isotopes.

The platform was mounted in a vacuum system that included a gas inlet system, a multichannel plate image intensifier, and a translating Faraday cup. The ion source was connected to the gas inlet system via a small-diameter Teflon tube such that the xenon was introduced directly into the ionization region of the ion source. The Faraday cup output was directed to an electrometer with output going to both a strip chart recorder and to a computer data acquisition system.

The vacuum system included a Bayard-Alpert pressure gauge and a residual gas analyzer (RGA) that enabled the composition and partial pressure of the gases in the vacuum system to be measured independently of the ion source being tested. The vacuum system was pumped with a turbo pump and an ion pump, configured such that either or both could be isolated from the ion source chamber. The base pressure was $3 \times 10^{-8}$ Torr.

The gas inlet system consisted of a leak valve connected to the sample inlet line via an isolation valve. Two sources of xenon were used. One was a small cylinder of natural xenon that provided several atmospheres to the leak valve, with no means to measure pressure or flow rate. This setup was used to calibrate the positions of the ion peaks after separation by the magnet and to establish the optimum operating conditions of the ion source. The second xenon gas source consisted of calibrated glass bulbs (15 cc) containing xenon at a known pressure $\left(0.6\right.$ Torr, $2.9 * 10^{17}$ xenon atoms), which were connected to the isolation valve with an O-ring compression fitting. The gas was introduced directly into the ion source through the Teflon tubing. This configuration allowed a known volume of xenon to be introduced to the ion source and was used to measure the ion source efficiency.

Figure 8 shows the ion beam profiles measured by translating the Faraday cup across the dispersing plane of the magnet and the SIMION-predicted ion beam profiles in cross-section at the Faraday cup location. The measured spacing between the peak centers and the width of the peaks correlates very well with the SIMION prediction, lending confidence in the mass assignments. In addition, the RGA showed the same major grouping of peaks; Figure 9 shows the spectrum measured with the RGA. The ion source efficiency was determined by operating the source at a near constant filament current ( $2.25 \mathrm{amps})$ and recording the xenon ion current until all of the xenon in the sample bulb was depleted (that is, until the 
xenon signal was at zero). The xenon signal was integrated over the total time to determine the total output. During the initial hours of operation, a filament current of 2.25 amps produced a xenon beam current of $\sim 600 \mathrm{pA}$. Figure 10 shows a typical fluence curve; the output is relatively constant over the first 8 hours and then tapers off as the source becomes depleted. The integrated signal corresponded to $1.07 * 10^{15}$ ions (singly charged xenon), and thus indicated an efficiency of $0.37 \%$. The emitted electron current was measured as a function of the filament temperature in a separate experiment by biasing the electron repeller to $60 \mathrm{~V}$ and connecting it to a floating electrometer. At $2.25 \mathrm{amps}$ of filament current, the measured electron output was $300 \mu \mathrm{A}$.

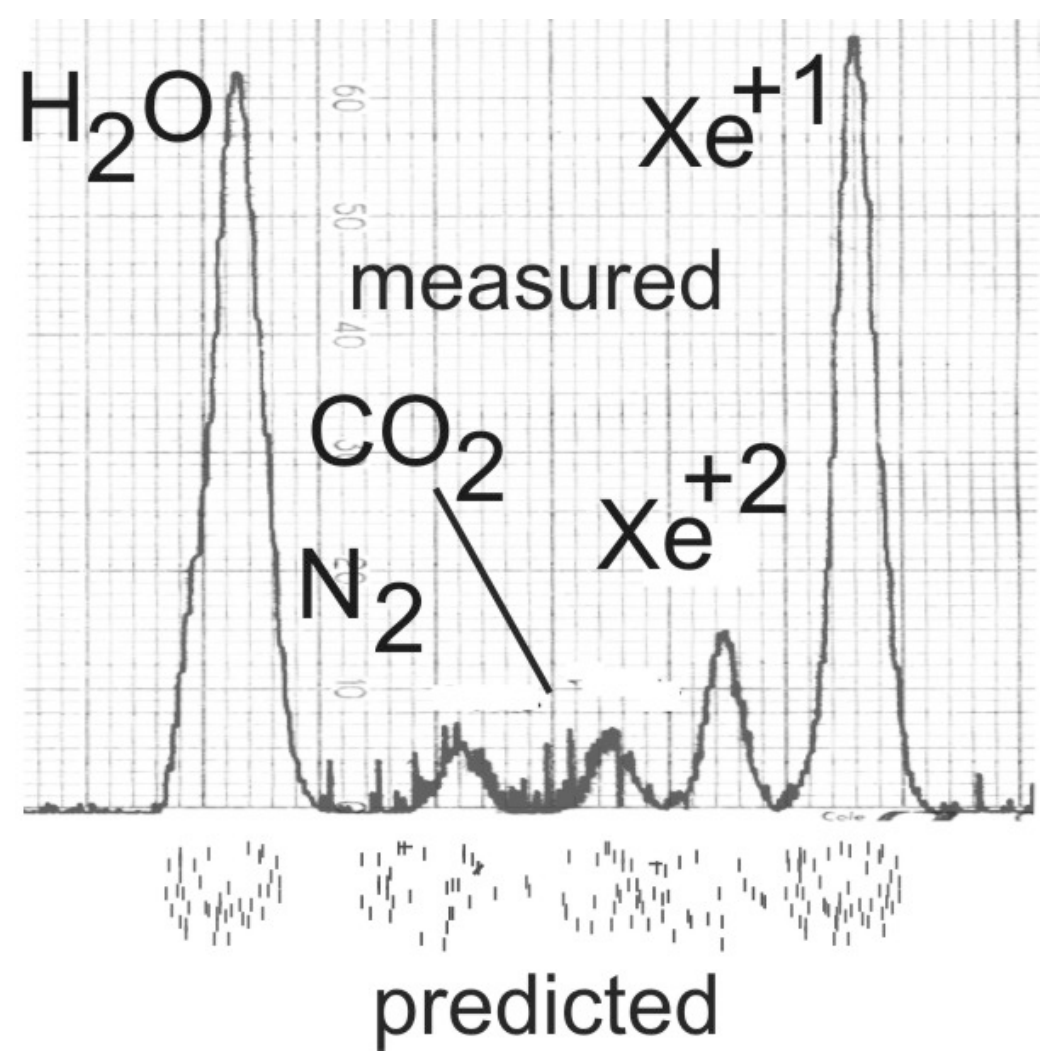

Figure 8. Measured mass spectrum (top) in the ion source test chamber and the SIMION-predicted peak cross-section positions (bottom).

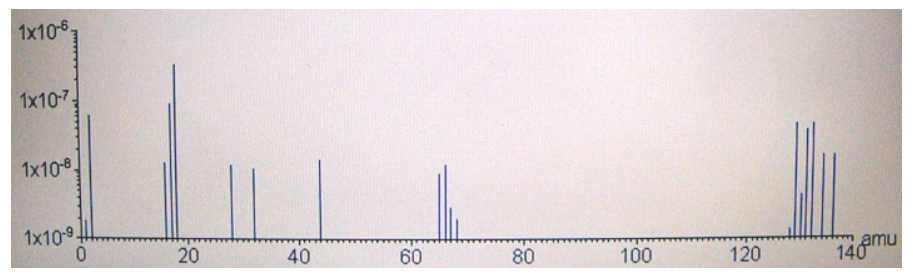

Figure 9. Mass spectrum of the source chamber taken with a residual gas analyzer. 


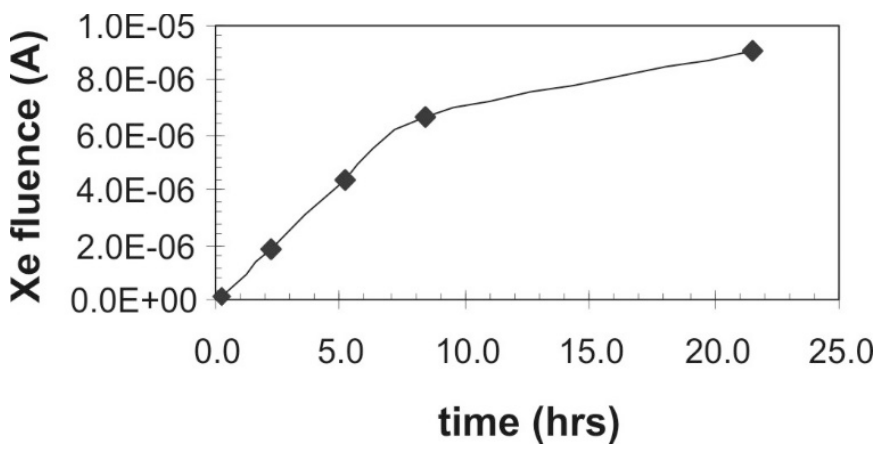

Figure 10. Measured fluence of xenon ions as a function of time.

\subsection{Isotope Separator}

The ion source and gun have been installed on a newly constructed xenon isotope separator. In the separator, the ${ }^{133} \mathrm{Xe}^{+}$ions are mass separated, post-accelerated to $15 \mathrm{kV}$, and implanted into an aluminum foil. The net efficiency of the mass separator is determined by the efficiency of the ion source, the transmission through the magnetic and electrostatic sectors, and the efficiency of implanting the ions into the foil.

Tests have been conducted to establish the sensitivity of the ion source using natural xenon. In these tests, the xenon was introduced directly into the vacuum system ion source housing (as opposed to directly into the ion source ionization cage), and the xenon pressure was measured using a nude ion gauge located in the source housing. It is assumed that, under these conditions, the xenon pressure in the ion source is the same as measured at the ion gauge. The xenon ion current (for ${ }^{129} \mathrm{Xe}$ ) was measured as a function of the pressure in the source housing, and the sensitivity was determined from the slope of the best fit line of the measured ion current versus pressure. Figure 11 shows the measured sensitivity curve and the linear equation fit to the data; the sensitivity is $\sim 24 \mathrm{~mA} / \mathrm{Pa}$. When introducing the xenon directly into the ion source, the maximum output current of xenon that could be sustained (without the source going into a discharge mode) was $\sim 7 \mathrm{nA}$. 


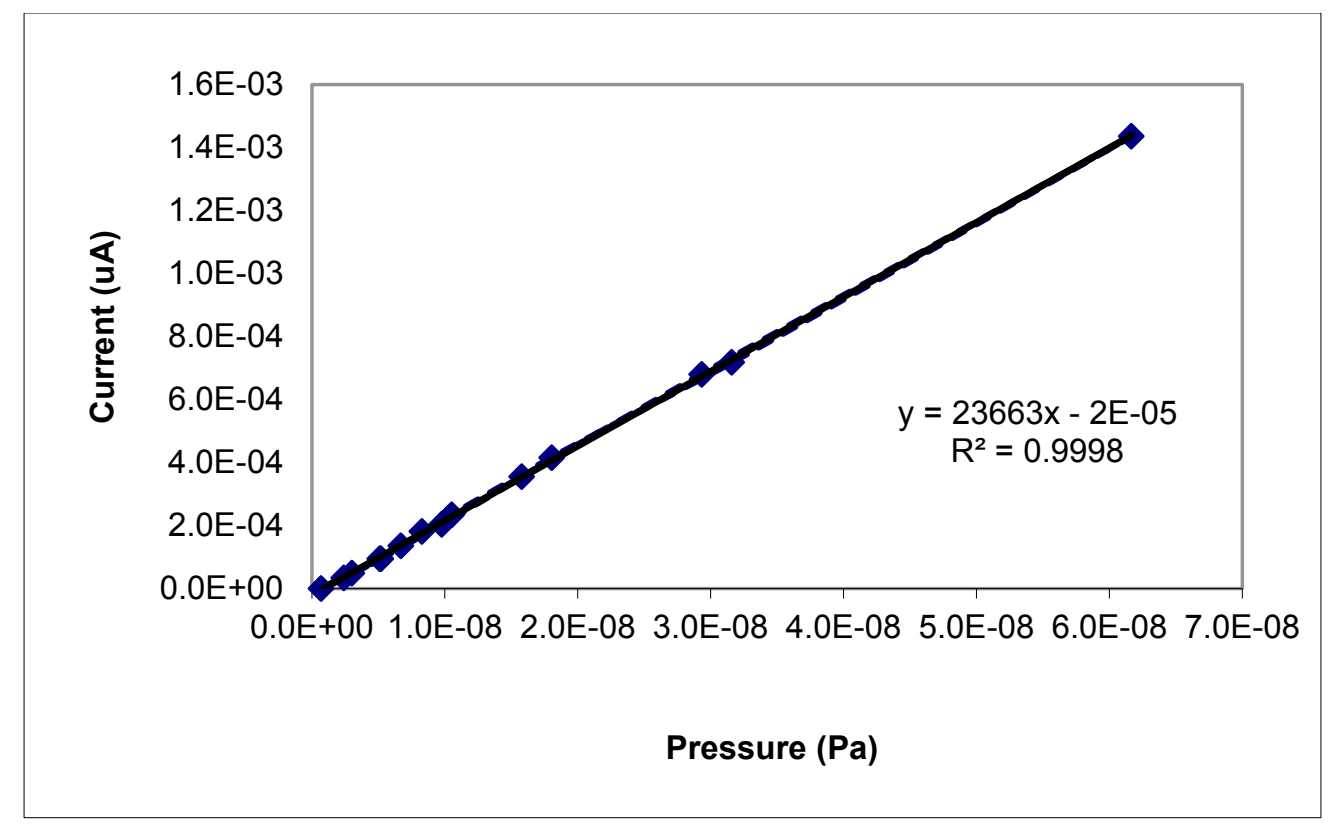

Figure 11. Measured total xenon ion current as a function of the xenon pressure in the ion source housing; the equation is for the best linear fit to the data.

The mass separator is used to isolate the radioactive isotopes of xenon for generation of standards. The radioactive xenon is a small fraction of the total gas in a sample; thus, the ion source has to be able to produce a xenon beam of adequate intensity to generate the required number of separated atoms in the presence of the carrier gases (air, natural xenon, and $\mathrm{CO}_{2}$, depending on the sample origin). A typical fission gas sample has about $2 \mathrm{ppm}$ xenon in carrier gas. In measurements conducted at this concentration, with natural xenon and air as the carrier gas, a ${ }^{129} \mathrm{Xe}$ current of $0.8 \mathrm{pA}$ was attained when the total ion current from the source was $3.5 \mathrm{nA}$.

Even with the expected large ion energy spread from this ion source, the xenon peaks were easily resolved in the mass separator. Figure 12 shows the SIMION-predicted kinetic energy distribution for ions created at typical experiment conditions ( 30 volts differential between the ionization cage and the extraction aperture); the energy distribution was not measured experimentally. Figure 13 shows the mass spectrum in the xenon mass range for natural xenon run at $5 \mathrm{kV}$ on the mass separator; the resolution is adequate to separate out the isotopes. The design goal was to ensure that ${ }^{133} \mathrm{Xe}$ could be isolated from ${ }^{131} \mathrm{Xe}$, which was easily accomplished. 


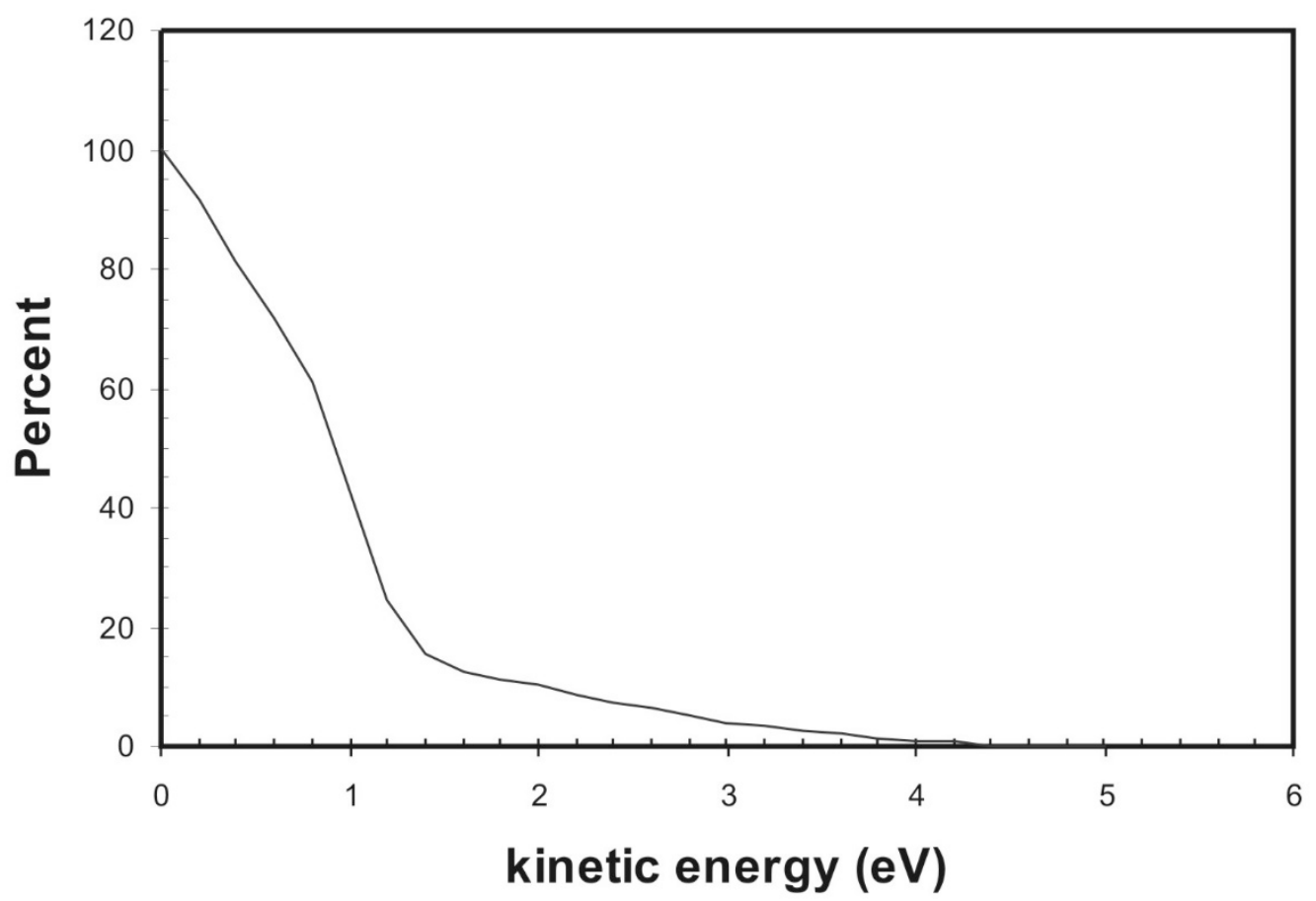

Figure 12. SIMION-predicted kinetic energy distribution for xenon ions generated with the ionization cage at 30 volts above the exit aperture. The plot displays the percent of ions as a function of the kinetic energy difference from the mean.

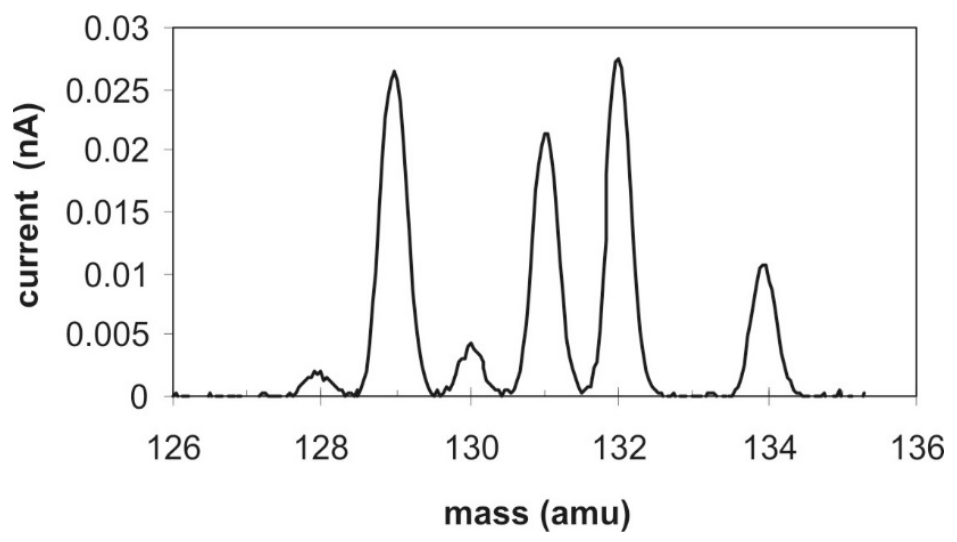

Figure 13. Mass spectrum of $\sim 2 \mathrm{ppm}$ natural xenon in air taken in the isotope separator.

The net efficiency of the mass separator, which is defined as the number of atoms implanted in the foil divided by the total number of atoms in the starting volume, was measured using ${ }^{133} \mathrm{Xe}$ (half-life $=$ 5.243 days). The implant efficiency was not measured, but previous studies ${ }^{11,12}$ indicate that it should be $100 \%$ at the energy and fluence levels applied. The starting material was fission gas containing a known quantity of readily available commercial medical xenon. It was continuously injected into the ion source

${ }^{11}$ G. Carter, D. G. Armour, S. E. Donnelly, D. C. Ingram, and R. P. Webb, "The Injection of Inert Gas Ions into Solids: Their Trapping and Escape," Radiation Effects, Vol. 53, No. 3-4, 1980, pp. 143-174.

${ }^{12}$ F. Brown and J. A. Davies, "The Effect of Energy and Integrated Flux on the Retention and Range of Inert Gas Ions Injected at Kev Energies in Metals," Canadian Journal of Physics, Vol. 41, No. 6, 1963, pp. 844-857. 
over a period of days, and the resulting ${ }^{133} \mathrm{Xe}$ beam was implanted into the foil until the source was exhausted. The foil was removed and gamma-counted to determine the quantity of ${ }^{133} \mathrm{Xe}$ in it. The net efficiency was $0.13 \%$. It is anticipated that this will increase after a new gas inlet system is installed, which will reduce the $\mathrm{CO}_{2}$ carrier gas concentration.

\section{Conclusion}

The cylindrical electron impact ion source offers a simple means for efficiently producing noble gas ions. The measured efficiency was $0.37 \%$ at conditions in which the source operated with a stabile output for 22 hours. It has operated unattended for periods of up to 48 hours, as well as for hundreds of total hours without any need for cleaning or for filament replacement. The sensitivity of the source is $\sim 24 \mathrm{~mA} / \mathrm{Pa}$ for xenon at an electron current of $300 \mu \mathrm{A}$. While the energy spread of the ions was not measured, modeling indicated it was $\sim 1.5 \mathrm{eV}$ for $90 \%$ of the output at nominal conditions. This would be unsuitable for high resolution mass spectrometry, but is acceptable as demonstrated for its intended operation in an isotope separator. The energy spread could be reduced, but only at the expense of the efficiency. 